\title{
DETERMINATION OF PATULIN TOXICITY AND ITS CONTROL IN ENVIRONMENT BY OPTICAL BIOSENSOR SYSTEMS
}

\author{
N.F. Starodub ${ }^{1}$, A.M. Katsev ${ }^{2}$, I.V. Pylipenko ${ }^{3}$, L.N. Pylipenko ${ }^{3}$, A,V, Nabok $^{4}$ \\ ${ }^{1}$ National University of Life and Environmental Science of Ukraine \\ 03041, Kiev, 15 Herojev Oboroni Str., nikstarodub@yahoo.com \\ ${ }^{2}$ Crimean State Medical University named S.I. Georgievsky, Simpheropol, Ukraine \\ ${ }^{3}$ National Academy of Food Technology, Odessa, Ukraine \\ ${ }^{4}$ Sheffield Halam University, Sheffield, England
}

Summary. The main principles of the determination of patulin toxicity by the bioluminescent and chemiluminescent tests with bacteria and Daphnia magna, respectively are described. Besides the quantitative control of this mycotoxin by SPR based immune biosensor with different algorithms of analysis are presented.

Key words: Mycotoxins, patulin, optical biosensors, determination of toxicity, quantitative control.

Introduction. Over five hundred toxic metabolites produced by more than 250 strains of microscopic fungis are known nowadays. The research in the field of mycotoxicology has shown that the intoxication by mycotoxins is a real and very serious danger for human. Moreover, the chronic mycotoxicosis significantly overshadows all known events of the acute forms of the poisoning in Japan, Russia, India, China and USA with the lethal outcome for thousands of people [1]. Among the mycotoxins being a widespread etiological factor for a number of nutritional toxicosis cases a special place is occupied by Patulin (shortly referred throughout the text as $\mathrm{P}$ ), lacton(4-hydroxi-4H-furo[3,2-c]pyran-2-(6H)-one), with the molecular mass of 154,12 and empiric formula $\mathrm{C}_{7} \mathrm{H}_{6} \mathrm{O}_{4}$. Firstly, $\mathrm{P}$ was obtained in 1943 from the culture of fungi of Penicillium patulum (synonym of Penicillium urticae as an antibiotic, and at the beginning it was considered as non-dangerous mycotoxin. Nevertheless in 1954 it was the reason for death of hundreds of cows in Japan [2]. Other strains of fungi, for example Penicillium: $P$. expansum, $P$. claviforme, $P$. urticae ( $P$. patulum), $P$. cyclopium, $P$. viridicatum, $P$. roqueforti; as well as strain of Aspergillus: A. clavatus, A. terreus, A. giganteus. Byssochlamys fulva, Byssochlamys nivea, P. mortensic and Paecilomyces may produce $P$ too $[3,4]$. Nevertheless, the fungi of $P$. expansum strain are the strongest producer of $P$ [5]. Revealed the high level toxicity, mutagenic and cancerigenic abilities in $P$ were the basis for the JECFA to restrict the maximal permissible dose of the $\mathrm{P}$ incoming in organism on the level of $0.4 \mathrm{ng}$ per $\mathrm{kg}$ of body mass per day [6]. National and International groups recommend the use apple food in which the residual content of $P$ is no more than $50 \mu \mathrm{g} / \mathrm{kg} \mathrm{[7]}$, at the same time many countries legislate the level of this mycotoxin in the juice from 20 to $50 \mu \mathrm{g} / \mathrm{kg}$ [8].

The different types of chromatography: one- and two-dimensional thin-layer chromatography - TLCh (for serial analysis), high performance liquid chromatography (HPLC) with ultraviolet- and fluorometric detection (for serial and control analysis) are used for the revealing, identification and quantitative evaluation of $\mathrm{P}$. Review of the methods of the P determination shows that the TLCh methods are more complex and provide less precision and sensitivity of the analysis in the comparison with the HPLC [9-11]. Isotopic analysis allows the determination of this mycotoxin at the concentration of $12 \mu \mathrm{g} / \mathrm{dm}^{3}[12,13]$.

$\mathrm{P}$ and others mycotoxins are low molecular weight substances, so they may act as antigens but not as immunogens. The latter ability they may acquire after conjugation with some proteins [14]. Generally, it is not a simple procedure and it often demands a contribution from highly professional of chemists. It was reported in [15] on obtaining polyclonal antibodies to $P$ although their specificity is not high. Unfortunately, the monoclonal antibodies to this mycotoxin are not commercially available at present in spite of a great practical interest in the development of different types of the immunochemical analysis, and particularly novel biosensoric instrumentation. Today demands of practice for the methods of the quantitative food control have grown very sharply. They include a number of positions, namely: the high level of the selectivity and sensitivity of the analysis, its rapidity and low cost, possibility of the observations in the field conditions and in the on-line and off-line regimes. Moreover, it is very important to check simultaneously several samples from the same or different sources, and, finally to provide electronic processing of the obtained results and their automatic transfer to the specialized laboratories or to the controlling offices. The fulfillment of all these demands is possible with the development and production of the principally new instrumental analytical devices such as Biosensors which may fulfill all practical demands not only in field of biotechnology but also in medical diagnostics and ecological monitoring [16- 
21]. At present there are exist a number of immune biosensors for the determination of low molecular weight substances in water and food. They include heavy metal ions, phosphororganic pesticides, atrazin, simazin, nonylphenol, T2 micotoxin, aflatoxin, deoxinivalenol and others [22-30]. It is a pity that we have not found any information regarding the development of biosensors for the control of $P$.

The main purpose of this article is the presentation of our experimental results on the determination of $\mathrm{P}$ toxicity and the development of both the ELISA-method and the immune biosensor based on the surface plasmon resonance for the control of the level of this toxin in the environment. At the same time, it was planed to solve some practical tasks related to the preparation of the required immune components and the development of the main algorithm of the analysis of $P$.

Experimental. The general toxicity of $P$ was characterized by optical biosensors based on the determination of the chemiluminescence $(\mathrm{ChL})$ of Daphnia magna living media (ChL-test) and by the bioluminescence (BL) of bacteria (BL-test) as it was described early [31, 32]. To detect the biochemical signal, special devices (both stationary and portable) were developed [33].

From the steric structure of $P$ (Fig. 1), one can see that, for the preservation of the antigen image of this mycotoxin, there is necessary to modify some chemical groups before their use in the process of conjugation with the proteins. All required modifications of $\mathrm{P}$ as well as and its conjugation with bovine serum albumin (BSA) and horse radish peroxidase (HRP) (both from Sigma, USA) were accomplished according to the procedures described in [34]. To obtain the specific antiserums, rabbits were immunized according to the following scheme. First, the immunization was performed by the intracutaneouse injection of the mixture containing the solution of $\mathrm{P}$-conjugate in isotonic $\mathrm{NaCl}$ and complete Friends adjuvant (Calbiochem, USA). In the course of three weeks, this procedure was repeated. In the next period, the immunization cycle was completed by two injections with the interval of 2 weeks but without the use of Friends adjuvant. The re-immunization was fulfilled in one month. The blood was taken in 12 days (variant of 1), after two injections of antigen (variant of 2) and in 2 weeks after re-immunization (variant of 3). Total fraction of immunoglobulin (Ig) was obtained using the well-known procedure with the application of sulphate ammonia precipitation.

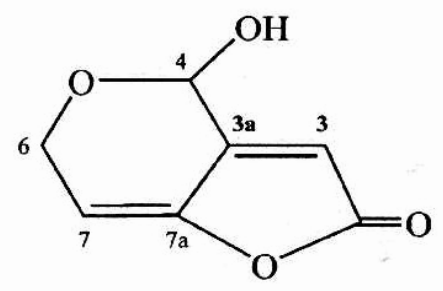

Fig. 1. Chemical steric structure of $P$.

The ELISA-method was used for the quantitative determination of $\mathrm{P}$ and it was carried out in two variations. In both variations, free $P$ was competed with one of its conjugate for the binding sites of the antibodies immobilized on the plate surface. The concentrations of both the free and conjugated $P$ were varied in the range from $0.1 \mathrm{ng} / \mathrm{mL}$ to $100 \mu \mathrm{g} / \mathrm{mL}$ (in the ratio 1:1). As a rule, $100 \mu \mathrm{L}$ of BSA-P conjugate at the concentration of $20 \mu \mathrm{g} / \mathrm{mL}$ in $0.1 \mathrm{M}$ sodium phosphate buffer ( $\mathrm{pH}$ 8.2), was introduced into the cells of the immunological plate for $18 \mathrm{~h}$ at $+4^{\circ} \mathrm{C}$. After that the cells were washed 3 times with $0,1 \mathrm{M}$ sodium phosphate buffer $(\mathrm{pH} 7,4)$ contained $0,14 \mathrm{M} \mathrm{NaCl}$ (PBS). To block free binding places $150 \mu \mathrm{L}$ of gelatin solution at the concentration of $0.1 \%$ was placed into cells and they were incubated for 30 min at $+37^{\circ} \mathrm{C}$. Then the cells were washed with PBS containing twin-20 (0.05\%) and filled with $50 \mu \mathrm{L}$ of the solution of $\mathrm{P}$ specific antiserum (preliminary dissolved by PBS with $0,05 \%$ of gelatin) and $50 \mu \mathrm{L}$ of free $\mathrm{P}$ solution (at the different concentration in methanol-water medium in ration 1:4). This mixture was incubated during 1 $\mathrm{h}$ at $+37^{\circ} \mathrm{C}$. Finally, the cells were washed in PBS and filled with the solution of goat anti-rabbit antibodies conjugated with HRP which was preliminary diluted by PBS in the ratio 1:1000. After $1 \mathrm{~h}$ of incubation at $+37^{\circ} \mathrm{C}$ the cells were washed three times in PBS and once in distilled water. The activity of HRP was determined in the presence of ortophenylendiamine and $\mathrm{H}_{2} \mathrm{O}_{2}(1,8 \mathrm{MM})$ in $30 \mathrm{mM}$ sodium acetate buffer, $\mathrm{pH}$ 4.5. Optical density of the solution was measured after 30 min with the help of "Sumal PE-2" instrument (Germany). The results obtained were presented in the values of optical units (O.U). Both variations had only one difference; in particular, it was related to the application of P-HRP conjugates which excluded the necessity of using the goat anti-rabbit antibodies conjugated with HRP.

Immune sensor analysis carried out on the SPR-4M instrument made in the Semiconductor Physics Institute (Ukraine). 40nm thick gold film was deposited by vapour deposition of metal on the glass surface of a prism. In the experiments, the surface of gold was modified with dodecanthiol (during $12 \mathrm{~h}$ ) or 
polyalylamine chloride to prevent protein destruction. The analysis was fulfilled in several ways: direct, competitive, and so called "to saturation".

The "direct" way was the simplest and it was carried out in the following way. At first, the initial SPR angular profile for PBS was recorded, and the SPR angle corresponding to the minimum reflection intensity was determined. Then the appropriate solutions of the P-conjugate or total IgG specified to this mycotoxin (both in the concentration of $1 \mathrm{mg} / \mathrm{mL}$ ) were introduced into the measuring cell (volume $10 \mu \mathrm{L}$ ). The adsorption of the above mentioned substances occurred at room temperature over a period of 30 min. The measuring cell was then rinsed with PBS and filled with BSA solution (1\%) to prevent nonspecific binding of the immune components on the transducer surface. After the incubation period of 10 min the measuring cell was washed with PBS and new SPR angular profile was recorded. It served as a reference line. Then, the measuring cell was filled with the $P$ solution of appropriate concentration. The incubation time was equal to $10 \mathrm{~min}$, which allowed the angle profile to reach saturation. After this, the measuring cell was washed with PBS containing $0.1 \%$ of Tween- 20 to remove all unbound components from the surface layer, thus preventing any interference with the measurements of the SPR angle caused by free analyte molecules in solution. "Competitive" way was fulfilled in two ways. Both of them were similar to the one described above, but in this case the P-conjugate or specific total Ig were immobilized in the measuring cell. Then it was filled with the mixture of total IgG specified to $P$ and free $P$, or by free $P$ and its conjugate at the following concentration: 1, 10,100, $1000 \mathrm{ng} / \mathrm{mL}$ and 1, 10, $100 \mu \mathrm{g} / \mathrm{mL}$. In both cases, free and conjugated molecules of $\mathrm{P}$ competed for the binding centres of the specific Ig. "To saturation" method had a difference that the specific Ig was immobilized in the surface of the measuring cell and then they reacted with free molecules of $\mathrm{P}$. The reminded centres of the specific Ig were saturated by the P-conjugate.

There is necessary to underline that in all cases when the specific Ig was immobilized on the surface of measuring cell an intermediate layer protein A was formed between the dodecanthiol (or polyalylamine sulphate) and the antibodies. It allows orienting of the binding centres of Fab-fragments of the specific Ig towards solution.

Determination of $P$ in real samples was carried out following the procedure described in [33]. Tomato juce was used as a model of real samples to which a different concentrations of $P$ were added.

Results and discussin. Preliminary results obtained early [34] have shown that $P$ belongs to strong toxic substances, later investigations revealed concrete details of this toxicity. The increase of $P$ concentration from 0.63 to $40 \mathrm{mg} / \mathrm{L}$ leads to sufficient decrease of $B L$ during 12-60 min of its influence on the Phosphorescenum phosphoreum Sq3 bacteria. The value of the effective toxic concentration (ETC) is in range of $0.63-1.25 \mathrm{mg} / \mathrm{L}$. With the prolongation of the $\mathrm{P}$ effect on bacteria this value is in range of 0.15$0.63 \mathrm{mg} / \mathrm{L}$ (Fig. 1). Decreasing the medium $\mathrm{pH}$ down to the lower physiological level (pH 5 - 5.5) the bacteria sensitivity to $\mathrm{P}$ has increased almost in one order of magnitude and it became equal to semilethal dose established in experiments with animals [35]. In the example, it was shown that the destruction of the intestinal barrier was observed at the $P$ concentration in apple juice on the level of 1 $\mathrm{mg} / \mathrm{kg}$. Bacteria of Vibrio fishery had higher level sensitivity in comparison to the bacteria Ph. phosphoreum $\mathrm{Sq} 3$ keeping the same effect related to the lowering of medium $\mathrm{pH}$.

The sensitivity of a standard international method based on $D$. magna to sodium bichromate was about $0.9-2.0 \mathrm{mg} / \mathrm{L}$. At the time, ChL-test was more sensitive (up to 3 orders of magnitude) and required on30 min for fulfillment in comparison with several days needed for standard procedure. $P$ in concentration from $0.01-1 \mathrm{mg} / \mathrm{L}$ aroused adaptive $D$. magna reaction (Fig. 2).

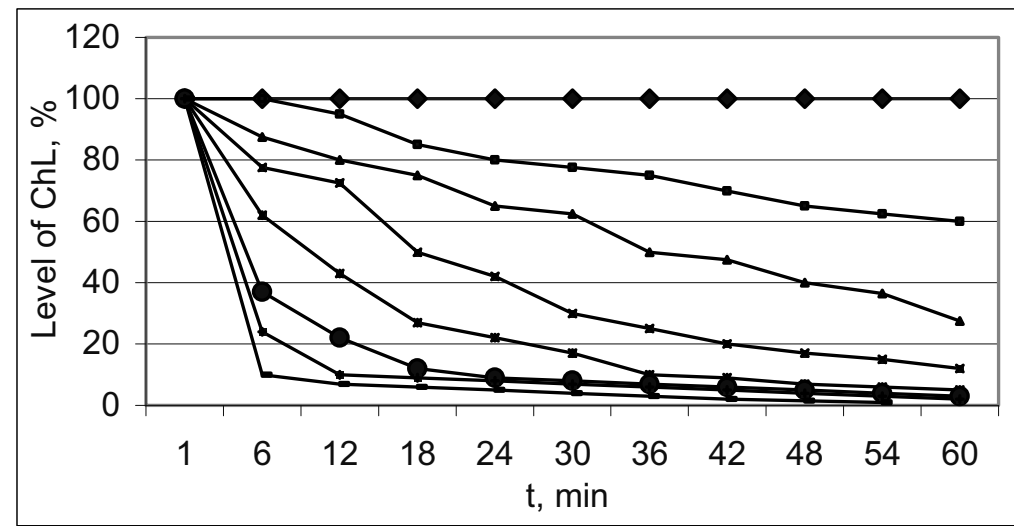

Fig. 1. Changes of $\mathrm{BL}$ of $P h$. phosphoreum after effect of different $\mathrm{P}$ concentrations during $90 \mathrm{~min}$. Curves from top-down reflect concentration: $0,0.63,1.25,2.50,5.00,10.0,20,0$ and $40.0 \mathrm{mg} / \mathrm{L}$, respectively

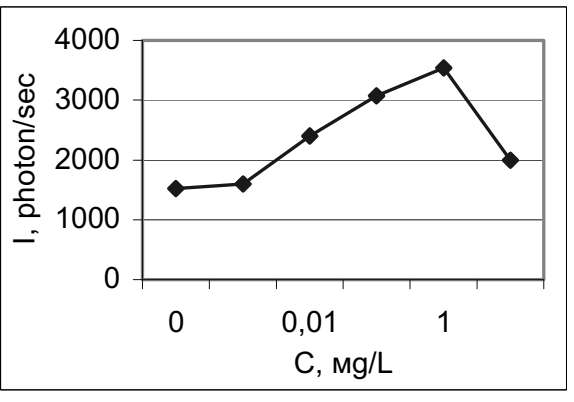

Fig. 2. Dynamics of ChL changes of daphnia medium staying at the different $P$ concentration. 
At the increase of $P$ concentration above $1 \mathrm{mg} / \mathrm{L}$, it was observed a sharp decrease of the ChL signal. Maybe in the first case $\mathrm{P}$ stimulates $D$ magna stomach system to excrete some substances which are able to stimulate ChL. In other experiment, $\mathrm{P}$ aroused daphnia mortality. It is necessary to mention that both proposed optical biosensors are characterized by high sensitivity and they can fulfill all practical demands in respect of estimation of total toxicity of the environmental objects prior the answering the question of the necessity of checking the presence of some groups of toxic elements or concrete toxins.

Characterization of the immunoreactivity of patulin conjugates and the determination of obtained antiserum specificity. The titer of antiserum was checked by the traditional method of the immune precipitation [14]. It was stated that it was similar for both conjugates and the achieved level was up to 1:64 in the case of the immunization according to the variation 3 (see details above). Certainly, in the use of variants 1 and 2 the obtained level of the titer was much high (in two and three times, respectively). The results of cross-reactivity of the obtained antiserums are given in Table 1. As one can see, all antiserums are characterized by high level of the specificity to $P$. That is why there is a basis for hope that they may provide specific determination of this mycotoxin in samples to be analyzed.

Table 1. Cross-reactivity of obtained antiserums to $P$.

\begin{tabular}{|c|l|c|c|}
\hline \multirow{2}{*}{ Items } & \multirow{2}{*}{ Substances } & \multicolumn{2}{c|}{$\begin{array}{c}\text { Cross-reactivity (\%) antiserums obtained after } \\
\text { immunization of conjugates: }\end{array}$} \\
\cline { 3 - 4 } & & A & B \\
\hline 1. & Patulin & 80 & 75 \\
\hline 2. & T2-mycotoxin & 5 & 7 \\
\hline 3. & Aflatoxin & 8 & 12 \\
\hline 4. & Searelenone & 7 & 0 \\
\hline 5. & Phtalate & 0 & 0 \\
\hline
\end{tabular}

Plot of the calibration curves by the ELISA-method for both types of the antiserums and total fraction of $\gamma$-immunoglobulins. Calibration curves for $P$ determination with the application of both types of specific antiserum are given in Fig. 3. As one can see, both antiserums allow $P$ revealing in the range of concentrations from 10 to $1000 \mathrm{ng} / \mathrm{mL}$. The purified total fractions of $\mathrm{Ig}$ have shown the same calibration curves as it was found for the appropriate antiserums. The observed difference between the antiserums is not sufficient for the analysis and it may be related to the differences in the concentration of the specific antibodies in the blood serum. Both calibration curves were plotted at the initial dissolving of the antiserums in the ratio of 1:500. Decreasing of this ratio down to 1:300 eliminated the difference observed early.

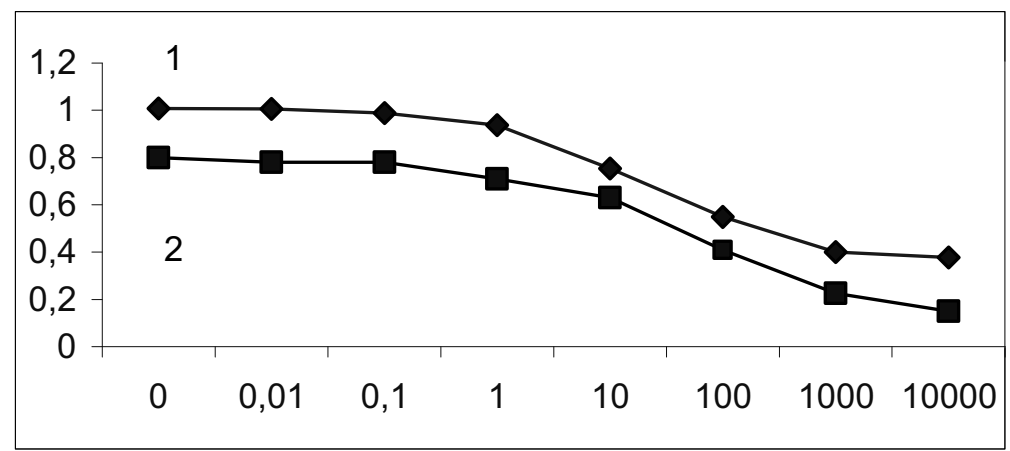

Fig. 3. Determination of $P$ by ELISA-method with the application of conjugate $A(1)$ and $B(2)$ as well as appropriate specific serums. Abscissa - $P$ concentration $(\mathrm{ng} / \mathrm{mL})$, ordinate - optical density.

Optical immune biosensor assay based on SPR for the determination of $P$. "Direct" analysis by SPR immune biosensor allows to us to evaluate $P$ at the concentration of $1 \mathrm{mg} / \mathrm{L}$ (Fig. 4) which is not practically significant level. "Competitive" method was much more sensitive (up to 2 orders of magnitude). It can provide the determination of $P$ at the concentration in the range from 0.01 to $10 \mathrm{mg} / \mathrm{L}$ (Fig. 5). Similar results were obtained at the realization of "to saturate" way for the P determination. There is necessary to underline that comparison of the application of polyelectrolites and dodecanthiol intermediate layers demonstrated the advantages of the former. Mainly it is connected with the stability of results of these measurements. The results of $\mathrm{P}$ determination in real samples (tomato juice) by "competitive" way are presented in Fig. 6 . It can be seen that we have possibility to reveal $P$ at the concentrations starting from $0.05 \mathrm{mg} / \mathrm{L}$ with the linear range of $0.05-10 \mathrm{mg} / \mathrm{L}$. We think that the observed difference between the standard solution and real sample is stipulated by some non-reversible sorption of $\mathrm{P}$ in organic phase. 


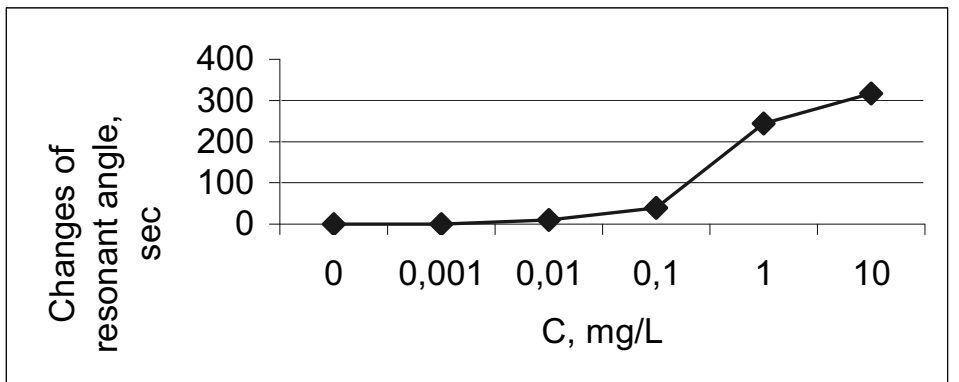

Fig. 4. Calibration curve for the P determination by SPR immune biosensor in "direct" way.

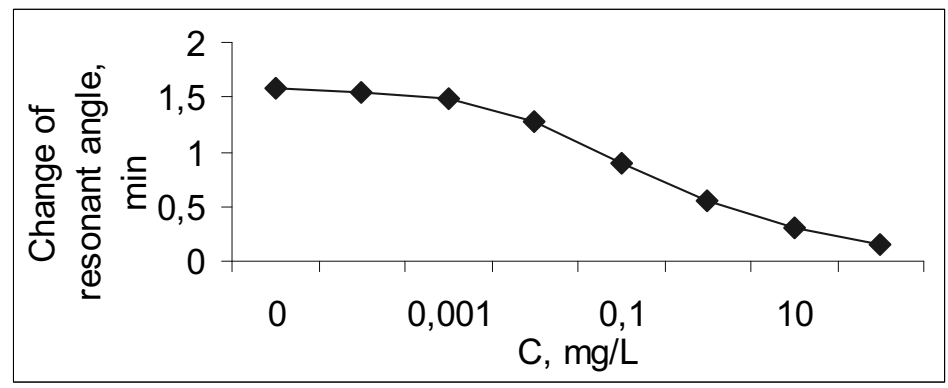

Fig. 5. Calibration curve for the P determination by SPR immune biosensor in "competitive" analysis.

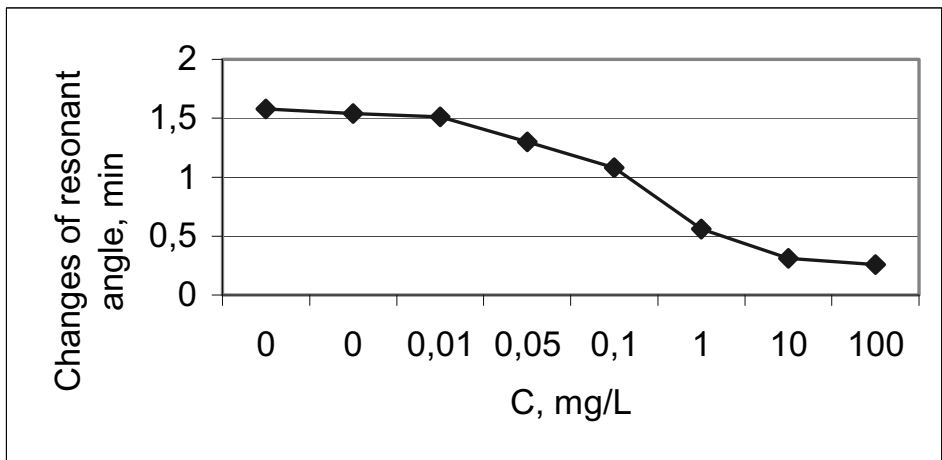

Fig. 6. Determination of P in tomato juice by SPR immune biosensor in "competitive" analysis.

Conclusion. The developed optical biosensor systems are able to fulfill all practice demands in respect of screening the environmental objects on total toxicity which may be stipulated by the $\mathrm{P}$ presence and further concrete evaluation of concentration of this toxin.

Acknowledgments. This work was supported by the Collaborative NATO Linkage grant (CBP.NUKR.CLG983381) and the grant of National University of Life and Environmental Science of Ukraine.

\section{Literature}

1. Starodub N. F., Pilipeko L. N., Pilipenko I. V., Egorova A. V. Mycotoxins and other low weight toxins as instrument of bioterrorists: express instrumental control and some ways to decontaminate polluted environmental objects. Timisoara Medical J., 2008, 58, N. 1-2, Issn 1583-5251.

2. Hopmans E.C. Patulin: a mycotoxin in apples. Perishables Handling Quarterly, 1997, 91, P. 5-7.

3. Charchenko S.N., Litvin V.P., Tarabara I.M. Manual on mycosis and mycotoxicosis of farming animals. Kiev, Uroghaj, 1982, 168p.

4. Tangni e K. , Theys R., Mignolet E., Maudoux M., Michelet J. Y., Larondelle Y. Patulin in domestic and imported apple-based drinks in Belgium: occurence and exposure assessment. Food Additives and Contamin, 2003, 20, N 5, 482-489.

5. Pittet A. Natural occurrence of mycotoxins in foods and feeds: a decade in review. Mycotoxins and Phycotoxins in Perspective at the Turn of the Millennium. Proceedings of the Xth International IUPAC symposium on Mycotoxins and phycotoxins, edited by W. J. de Koe, R. A. Samson, H. P. Van Egmond, J. Gilbert and M. Sabino (Wageningen: W. J. de Koe), 2001, 153-172.

6. JECFA, Toxicological Evaluation of Certain Food Additives and Contaminants in Food: Patulin. Forty-fourth Meeting of the Joint FAO/WHO Expert Committee on Food Additives. WHO Food Additives Series 35 (Geneva: WHO), 1996, $377^{\wedge} 102$ 
7. Association of the Industry of Juices and Nectars from Fruits and Vegetables of the EEC, Code of Practice: General, Physical, Chemical and Microbiological Criteria for Fruit and Vegetable Juices and Nectars in the European Community, 1990.

8. Food and Agricultural Organization,World Health Organization, Evaluation of Certain Food Additives and Contaminants. 44th Report of the Joint FAO/WHO Expert Committee on Food Additives, Tech. Report Series, WHO, Geneva, 1995, v. 859. Food and Agricultural Organization, World Health Organization, Evaluation of Certain Food Additives and Contaminants, 44th Report of the Joint PAO/WHO Expert Committee on Food Additives, Tech. Report Series, Vol. 859, WHO, Geneva, 1995. Food and Agricultural Organization, Worldwide regulations for mycotoxins, a compendium. FAO Food and Nutrition Paper No. 64, 1996.

9. Manual P 4.1.1672-03. 4.1. Methods of control. Chemical factors. Federal centre of state sanitary-epidemiological inspection of Ministry of Health of Russia, M, 2004, 240p.

10. Manual on methods of analysis of quality and safety of foods // Red. I.M. Skurichina, V.A. Tutel'jan. - M. - Brandes, Medicine. - 1998. - 348p.

11. GOST 28038-89. Products of fruits and vegetables handing work. Method of determination of patulin mycotoxin. $8 p$.

12. Rychlik M., Schieberle P. Quantification of the mycotoxin patulin by a stable isotope dilution assay. J. of Agricult. and Food Chem., 1999, 47, 3749-3755.

13. Rychlik, M. Rapid degradation of the mycotoxin patulin in man quantified by stable isotope dilution assay. Food Additives and Contamin., 2003, 20, N 9, 829-837.

14. Kul'berg A.Ja. Molecular immunology. - M., High Education, 1985, 288c.

15. McElroy L.J., Weiss C.M. The production of polyclonal antibodies against the mycotoxin derivative patulin hemiglutarate. Can. J. Microbiol, 1993, 39, 861.

16. Starodub M.F., Starodub V.M. Immunosensors: витоки виникнення, achievements and perspectives. Ukr. Biochem. J., 2000, 72, N 4-5, 147-163.

17. Starodub V.M., Starodub N.F. Electrochemical and optical biosensors: origin of development, achievements and perspectives of practical application. In book of NATO series "Novel processes and control technologies in the food industry", Ed. Bozoglu F. at al., Amsterdam, 2001, 63-94.

18. Starodub N.F., Starodub V.N. Biosensors and control of pesticides in foods. J. Water Chemistry and Technology, 2001, 23, N 6, 612-638.

19. Starodub N.F., Starodub V.N. Express control of toxic substances and pathogenic microorganisms. Immune analysis and immune sensors. Ukr. Biochim. J., 2002, 74, N 4, 5 - 23.

20. Starodub N.F., Starodub V.M. Biosensors on the basis of photoluminescence of porose silicon. Overall characteristics and application for the medical diagnostics. Sensors Electronics and Microsystem Technologies, 2004, 2, 63-83.

21. Starodub N.F., Starodub V.M. Biosensors on the basis of photoluminescence of porose silicon. Application for the monitoring of environment. Sensors Electronics and Microsystem Technologies, 2005, 1, 63-71.

22. Nabok A.V., Ray A.K., Starodub N.F., Dowker K.P. Enzyme/indicator optrodes for detection of heavy metal ions and pesticides. Biochemical and biomolecular sensing. Ed. Liberman R.A. Proceedings SPIE, 2000, 4200, 32-41.

23. Starodub N.F., Dzantiev B.B., Starodub V.M., Zherdev A.V. Immunosensor for the determination of the herbicide simazine based on an ion-selective field-effect transistor. Anal. Chim. Acta, 2000, 424, 37-43.

24. Starodub N.F., Starodub V.M. Biosensorics control of water pollution by some chemical organic substances. J. Water Chem. and Technol., 2002, 24, N 5, 447-472.

25. Nabok A.V., Tsargorodskaya A., Hassan A.K., Starodub N.F. Total internal reflection ellipsometry and SPR detection of low molecular weight environmental toxins. Appl. Surface Sci., 2005, 246, 381-386.

26. Daly S.J., Keating G.J., Dillon P.P., Manning B.M., O’Kennedy R., Lee H. A., Morgan R.A. Development of surface

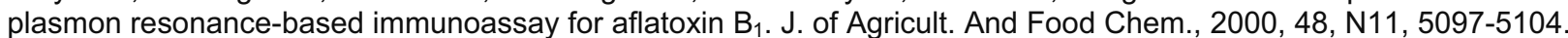

27. Mullett W., Lai E.P.C., Yeung J.M. Immunoassay of fumonisins by a surface plasmon resonance biosensor. Anal. Biochem., 1998, 258, 161-167.

28. Tudos A.J., Lucas-van den Bos E.R., Stigter E.C.A. Rapid surface plasmon resonance-based inhibition assay of deoxynivalenol. J. of Agricult. And Food Chem., 2003, 51, N 20, 5843-5848.

29. Starodub N.F., Nabok A.V., Tsargorodskaya A., Gojster O.S., Khmelnitsky G.O. Control of T2 mycotoxin in solutions and foods by biosensors based on SPR and TIRE. - In Proc. Sensor+Test 2006, Nurenberg, Germany, 2006, 87-92.

30. Nabok A.V., Tsargorodskaya A., Holloway A., Starodub N.F., Gojster O., Michal'chenko V. Registration of T2 Mycotoxin with Total Internal Reflection Ellisometry. Biosensors and Bioelectronics, 2007, 22, 885-890.

31. Kazev A., Gojster O., Starodub N. Effect of T2 mycotoxin on the intensity of bacteria bioluminescence. Ukr. Biochem. J., 2003, 75, N 3, 99-103.

32. ISO 6341:1996(E), Water quality - Determination of the mobility of Daphnia magna Straus (Cladocera, Crustacea) Acute toxicity test.

33. Starodub N.F., Kanjuk M.I., Ivashkevich S.P., Pilipenko L.N., Egorova A.V., Pilipenko I.V. Patulin toxicity and determination of this toxin in environmental objects by optical biosensor systems. Abstr. of 3-th Intern. Sci.\&Tech. Conf. "Sensor Electronics and Microsystem Technol.", 2-6 Jun. 2008, Odessa, Ukraine, 2008, 237-238.

34. de Champdore M., Bazzicalupo P., De Napoli L., Montesarchio D., Di Fabrio G., Cocozza I., Parracino A., Rossi M., D'Auria S. A new competitive fluorescence assay for the detection of patulin toxin. Anal. Chem., 2007, 79, $751-757$.

35. Manfoud R., Maresca M., Garmy N., Fantini J. The mycotoxin patulin alters the barrier function of the intestinal epithelium: mechanism of action of the toxin and protective effects of glutathione. Toxicol. and Appl. Pharmacol., 2002, 181, 209-218. 